\title{
Emerging Impact on Graduation Rates/Times From A Summer Engineering Enrichment Program
}

\section{Dr. Robert W. Whalin, Jackson State University}

Dr. Robert W. Whalin, Professor of Civil and Environmental Engineering, and Director, Coastal Hazards Center, Jackson State University. He is Director Emeritus of the Engineer Research and Development Center, Vicksburg, MS. He received his PhD in Oceanography from Texas A\&M University in 1971 and is a Registered Professional Engineer. Dr. Whalin was Director of Army Research Laboratory (19982003; Adelphi, MD), and Technical Director /Director of Waterways Experiment Station (1985-1998; Vicksburg, MS). He has authored/co-authored over a hundred technical papers and reports during his career in private industry, government and academia. His current research interests are nearshore wave transformations, coastal structures, tsunami inundation, hurricane surges, high performance computing, and engineering education.

\section{Ms. Qing Pang, Jackson State University}

Qing Pang, Instructor, Department of Electrical and Computer Engineering, College of Science, Engineering and Technology, Jackson State University. 


\title{
Emerging Impact on Graduation Rates/Times \\ From a Summer Engineering Enrichment Program
}

\begin{abstract}
A sustained summer engineering enrichment program was initiated in 2009 with the objective of increasing graduation rates and decreasing time to graduate for first time freshman with Math ACT scores from 17-25 which comprises the preponderance of our freshman engineering class. The ten week summer program included College Algebra the first summer term, Trigonometry plus an informal non-credit Introduction to Engineering the second summer term, periodic trips to engineering employers, supervised daily study sessions and dormitory accommodations facilitating formation of a community of engineering learners. The first five summer cohorts were attended by 172 engineering majors and 128 or $74 \%$ continued in a School of Engineering major in the fall following the summer program. Three or $12.5 \%$ of the 24 in the 2009 cohort graduated as engineers in May 2013 (4 years). This compares with a four year graduation rate of less than $5 \%$ for all first time freshman engineering majors at our university since the first engineer graduated in May, 2005 (over 300 graduates). Four more students in the 2009 cohort graduated as engineers in December 2013 while two additional students graduated in other STEM majors in December 2013. The overall graduation results for the 2009 cohort to date are that seven, or $29 \%$, graduated as engineers in $4 \frac{1}{2}$ years and nine or $37.5 \%$ graduated in a STEM major in $4 \frac{1}{2}$ years. Eight 2009 cohort students remain enrolled in the university (3 STEM and 5 non-STEM majors) and seven or $29 \%$ of the 2009 cohort have left the university without graduating. An analysis of the 2010 summer cohort reveals that seven students completed Senior Design I in Fall 2013 and are projected to graduate in four years (7/37 or 19\%) in May 2014. We believe these emerging graduation rate data imply that first time freshman engineering majors with math ACT scores from 17-25 may achieve six year graduation rates nearly comparable to those with higher scores with the benefit of a summer bridge program focusing on enhancing mathematics readiness and becoming a community of engineering learners. In summary, evidence is emerging (after 5 summer cohorts) that, for first time freshman students in the ACT Math score range from 17-25, we can increase the 4 year graduation rate nearly fourfold from about $5 \%$ to $19 \%$ and potentially increase the overall engineering graduation rate twofold from about $25 \%$ to near $50 \%$. Simultaneously, the average time to graduate is reduced by nearly a year to less than $4 \frac{1}{2} 2$ years (from about 5.2 years).
\end{abstract}

\section{Background}

A projected long term summer engineering enrichment program was started in summer 2009 with an objective of increasing retention rates and graduation rates (in a School of Engineering major) for first time freshman with ACT Math scores in the range of 17-25. A decrease in time to graduate was expected. To be eligible to apply for admission to the summer program, students must have applied and been accepted to attend the university during the fall semester with a major in the School of Engineering [Civil Engineering, Computer Engineering, Computer Science, Telecommunications Engineering or (since fall 2012) Electrical Engineering]. Students 
in the summer program are enrolled for credit in College Algebra during the first summer term and in Trigonometry and a non-credit Introduction to Engineering course the second summer term. Classes meet in the mornings at 9am every day and study periods, monitored by Graduate Students who attend the morning lecture, meet in the afternoons. A learning community atmosphere is created as the students are housed together in a dormitory and evening and weekend activities are planned. Periodic visits to engineering employers are arranged for the cohort. The students meet upper class and graduate engineering students, alumni from previous summer cohorts provide formal lectures and all expenses (tuition, room and board, and books) are paid from a US Department of Education Title III grant. Two previous papers by the authors provided some of these data that are included herein for completeness. Results in the papers indicate that one, two, and three year retention rates were increased by $22 \%, 25 \%$, and $29 \%$ respectively when compared with students in the identical ACT Math score group (17-25) who did not participate in the summer engineering enrichment program. Additionally, although the data are limited, it appears that SEEP engineering students with ACT Math scores from 20-25 achieve a greater retention rate (by about 12\%, 14\%, and 23\% for 1 year, 2 year, and 3 years respectively) than their classmates with ACT Math scores of 17-19. Many summer bridge/enrichment programs with various objectives/approaches (mostly aimed at increasing retention of engineering majors) have been implemented [1, 2, 3, 4, 5, 6, 7, 8, 9, 10, 11, and 12]. Most of the programs appear to have a nominal length of 2-4 weeks which is likely due to program cost and sustainment of funding sources. To the best of our knowledge, none have been undertaken for the full 10 week summer term, enrolled students in College Algebra and Trigonometry for credit and sustained for a number of years.

We should reiterate that our university serves a first time freshman population with significantly different ACT scores (or the SAT equivalent) from most Colleges of Engineering. Any student admitted to the university may select one of our engineering majors as their field of study. Nearly $70 \%$ of first time freshman students who choose one of our engineering majors have ACT Math scores in the 17-25 range. The ACT Math scores of the remaining engineering majors have changed markedly from the first engineering class in 2000 to the present. Like many other universities, we place students with ACT Math scores above 25 in Calculus I (unless they qualify to be placed in Calculus II by Advanced Placement test scores). Those with ACT Math scores below 17 are placed in an Intermediate Algebra developmental class. In 2000, most other freshman engineering majors had ACT Math scores below 17 while in 2013 others were about equally divided between those with scores below 17 and those with scores above 25 .

\section{Baseline Data for Program Impact}

Five cohorts (2009-2013) totaling 172 students participated in the summer engineering enrichment program. All participants had ACT Math scores from 17-25 inclusive, and 95\% (163/172) passed both Algebra and Trigonometry with grades of C or better. A number of students (44 or $25.6 \%$ ) changed their majors to one with a curriculum requiring less mathematics courses (usually Industrial Technology, Biology or a major in the College of Business) to begin the fall semester. We believe this is a positive result since these students changed majors to a curriculum more to their liking early enough to not affect their time to graduate. These data are displayed in Table 1. 


\begin{tabular}{|l|c|c|c|c|}
\hline \multicolumn{5}{|c|}{ Table 1 Baseline Data } \\
\hline Cohort & $\begin{array}{c}\text { Number in } \\
\text { Summer Program }\end{array}$ & $\begin{array}{c}\text { Cumulative } \\
\text { Total }\end{array}$ & $\begin{array}{c}\text { Number Changing } \\
\text { Major }\end{array}$ & $\begin{array}{c}\text { Cumulative Total } \\
\text { Changing Major }\end{array}$ \\
\hline 2009 & 24 & 24 & 10 & 10 \\
\hline 2010 & 37 & 61 & 4 & 14 \\
\hline 2011 & 34 & 95 & 12 & 26 \\
\hline 2012 & 38 & 133 & 11 & 44 \\
\hline 2013 & 39 & 172 & 7 & \\
\hline
\end{tabular}

Academic performance [in Calculus, Physics and Chemistry] of the students who remained engineering majors (128 or 74.4\%) in the fall semester following the summer enrichment program is enumerated in a previous publication. These data indicate that substantially more than half the students who complete both Calculus II and Physics II with a C or better, tend to graduate in an engineering major within the next three academic years. The number of students who enrolled in the summer program (172) is used as the base for computing emerging graduation rates and time to graduate because we are comparing these rates with the comparable population (17-25 ACT Math scores) of engineering majors who began the fall semester (20092013) without the benefit of the summer enrichment program.

\section{Emerging Impact on Graduation Rates/Times to Graduate}

Since we only have 4 years and one semester of data for the 2009 summer cohort on which to compute graduation rates, the adjective emerging was used to describe results to date. In addition to graduation rates, one, two, three and four year retention rates in an engineering major, will be displayed as well as graduation rates in a STEM major and in any university major. Figure 1 shows historical (since program start) first time freshman (with ACT Math scores from 17-25) one year and two year retention rates in an engineering major. The first engineering graduates were in May 2005 and the number of first time freshman is shown directly above the academic year (from 2000 to 2012). Students who were in the 2009-2012 Summer Engineering Enrichment Program (SEEP) cohorts are excluded from Figure 1 since these (non-SEEP) retention rates will be compared with those for the SEEP cohorts. 


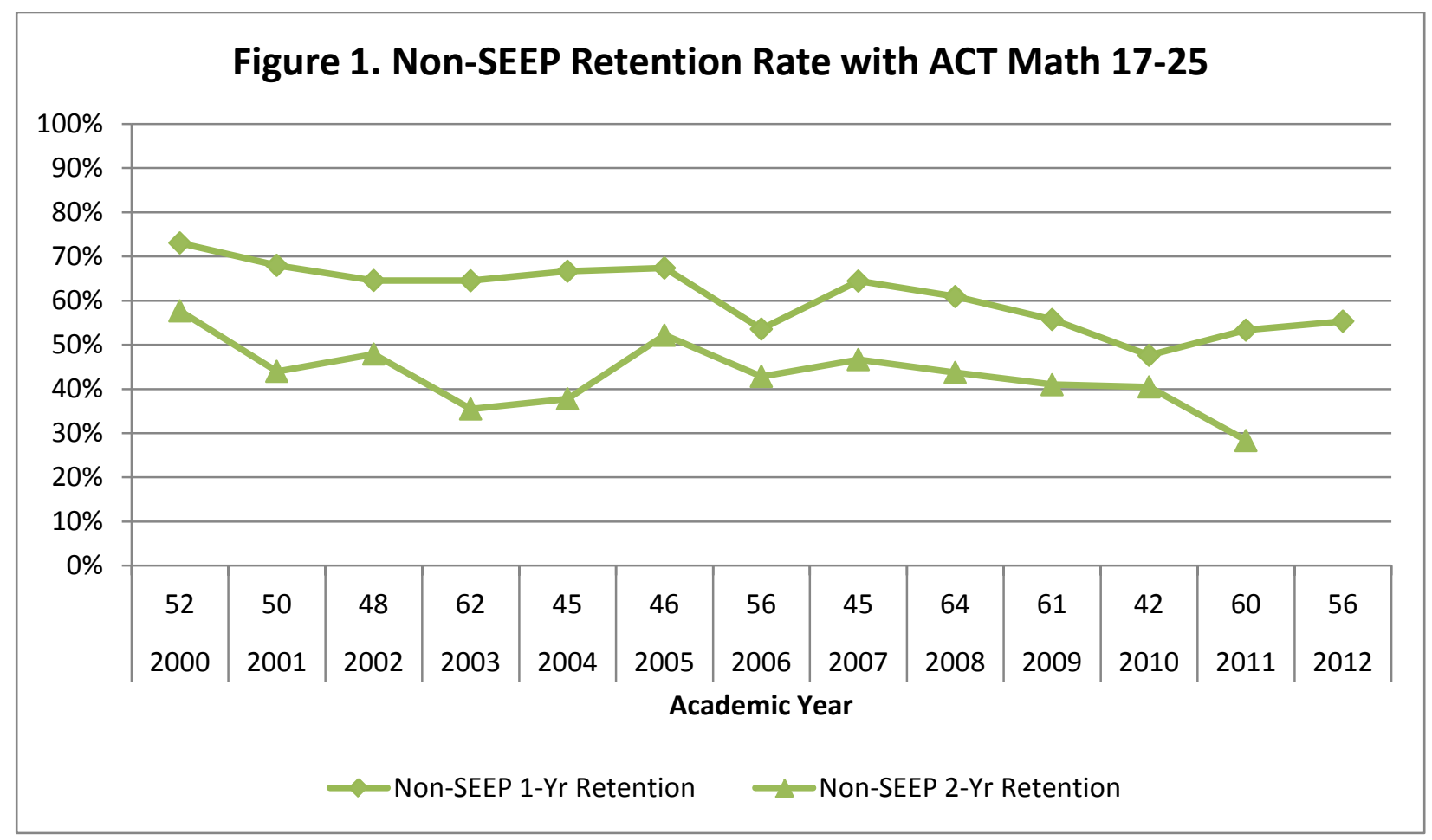

Figure 2 shows the one, two, three and four year retention (in an engineering major) rates for students in each of the summer cohorts (2009-2012). The number of students in each cohort upon which the retention rates were computed was based on the number of students in the summer cohort (Table 1, column two).

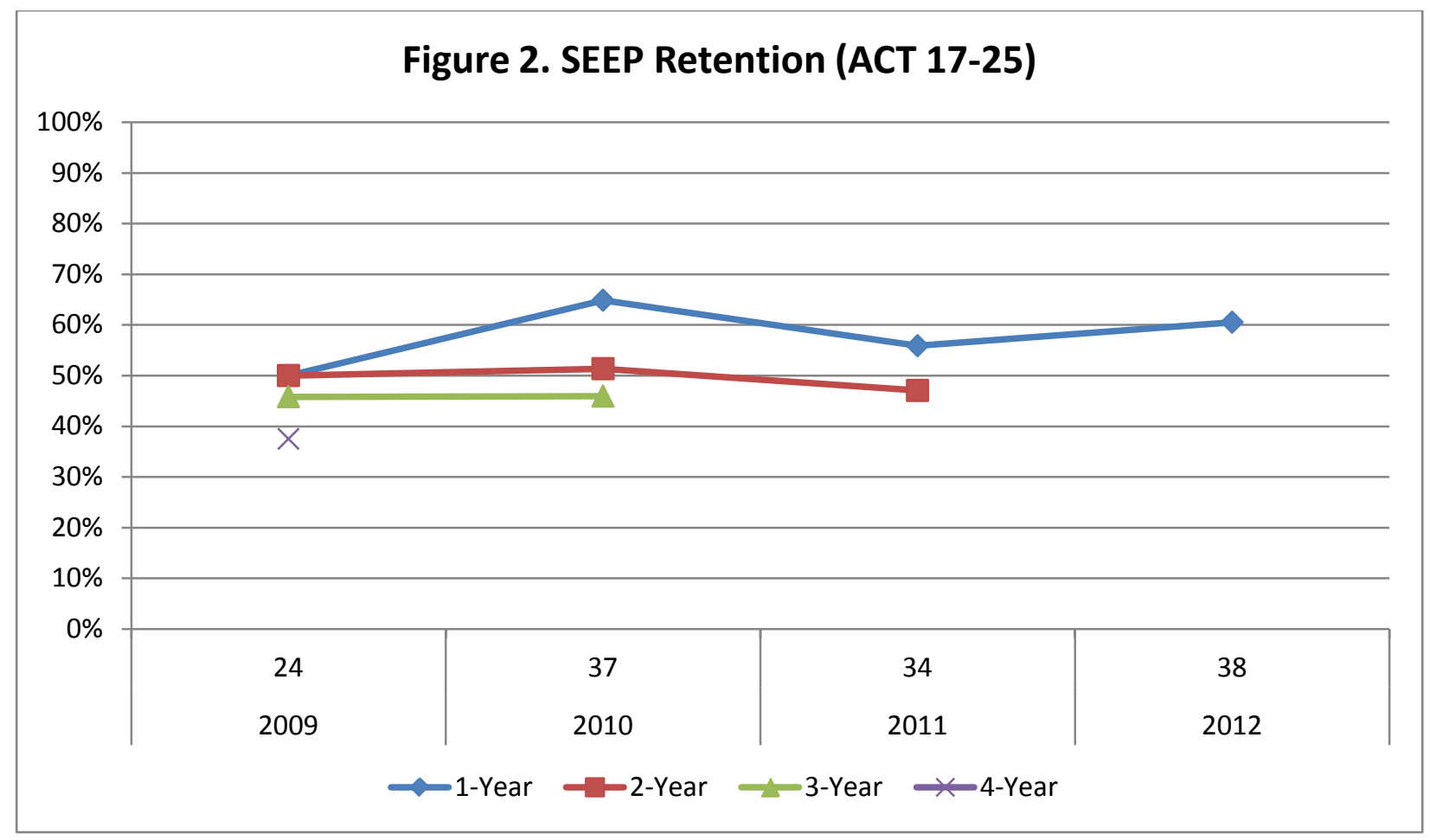


Retention data are summarized in Table 2 which displays a side by side comparison of one, two, three, and four year retention rates for all summer cohorts relative to retention rates for first time freshman School of Engineering majors who did not attend the Summer Engineering Enrichment Program (SEEP) during identical years in the 2009-2012 period. From 2009 to 2012, 219 first time freshman began their college career as engineering majors in the fall semester. This is the total number of students used to compute one year retention rates illustrated in Table 2.

Analogously, the total number of students upon which two year retention rates were calculated in table 2 (2009 to 2011) was 163 (219-56) and the total number of students for calculating three year retention rates in table 2 (2009-2012) was 103 (163-60). Data for four year retention for non-SEEP students were unavailable. The zero year retention data represent the number of SEEP students who remain enrolled in an engineering major in the fall semester following the summer program. The four year SEEP retention data include students who graduated (7 of the 9).

\begin{tabular}{|c|c|c|c|}
\hline \multicolumn{5}{|c|}{ Table 2 Engineering Retention Rates for SEEP vs. Non-SEEP Students } \\
\hline Retention & Non-SEEP Students & SEEP Students & Difference \\
\hline 0 Year & $219 / 219=100 \%$ & $128 / 172=74 \%$ & N/A \\
\hline 1 Year & $117 / 219=53 \%$ & $72 / 133=54 \%$ & $8 \%$ \\
\hline 2Year & $59 / 163=36 \%$ & $42 / 95=44 \%$ & $9 \%$ \\
\hline 3 Year & $33 / 103=32 \%$ & $25 / 61=41 \%$ & \\
\hline 4 Year & Not available & $9 / 24=37.5 \%$ & \\
\hline
\end{tabular}

Table 3 contains the 4 Year and 4.5 Year graduation rates for the 2009 SEEP cohort and the projected 4 year graduation rate for the 2010 SEEP cohort. Figure 3 shows 4 to 8 year graduation rates for First Time Freshman School of Engineering majors since program initiation in 2000.

\begin{tabular}{|l|l|l|c|}
\hline \multicolumn{5}{|c|}{ Table 3 Engineering Graduation Rates } \\
\hline Non SEEP 2009 & Projected 2010 & Actual SEEP 2009 & Projected 2010 \\
\hline 4 Year 9/96=9.4\% & No projection & $3 / 24=12.5 \%$ & $7 / 37=19 \%$ \\
\hline 4.5 Year $/ 96$ & No projection & $7 / 24=29 \%$ & No Projection \\
\hline
\end{tabular}

Figure 3 depicts all non-SEEP School of Engineering graduates for each class of First-TimeFreshman since program inception in 2000. Averaged from 2000-2009, the four year graduation rate is about $5 \%$, whereas it is $9.4 \%$ for the 2009 class. Using the average four year graduation rate for non-SEEP students of 5\% and the projected 2010 SEEP cohort graduation rate of 19\% would tend to imply that the SEEP program could possibly increase 4 year graduation rates nearly fourfold. Analogously, the nominal non-SEEP six year graduation rate in Figure 3 is about $22 \%$ since program inception and a projected SEEP six-year graduation rate could be in the $40 \%-50 \%$ range resulting in a nearly two fold graduation rate increase. 


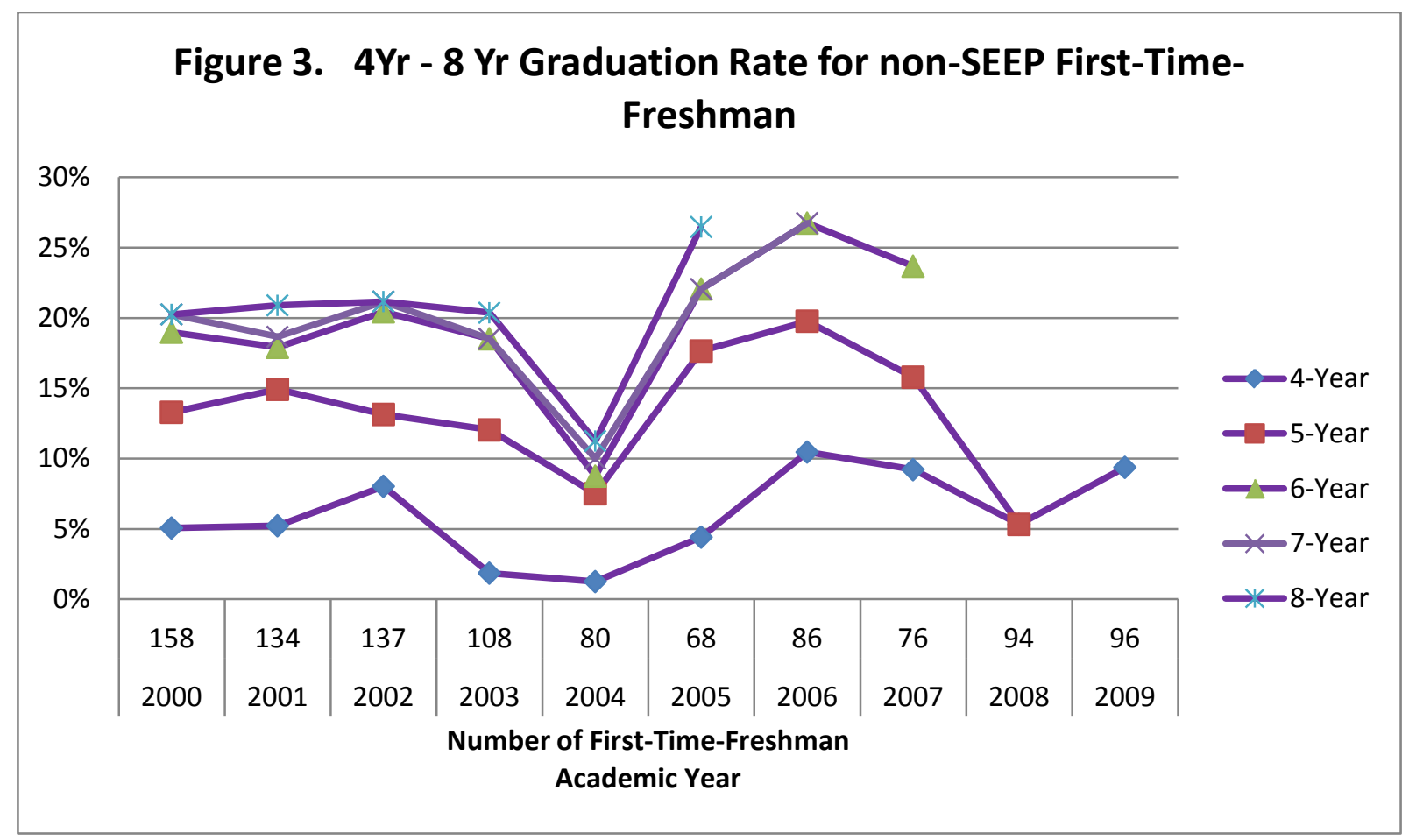

The 2009 SEEP Cohort only has two students remaining as engineering majors. Consequently, the upper limit of engineering graduates is $9 / 24$ or $37.5 \%$. Ten 2009 SEEP students were enrolled during the Fall 2013 Semester and two graduated in December 2013 (one in Industrial Technology and one in Earth System Sciences), both are STEM graduates. Therefore 9/24 or $37.5 \%$ of the 2009 cohort graduated as STEM majors. Three other STEM majors are enrolled for the spring 2014 semester; two in Computer Engineering and one in Biology. The upper limit of STEM graduates for the 2009 cohort is $12 / 24$ or $50 \%$. Additionally, there are five members of the 2009 cohort enrolled in non-STEM majors for the spring 2014 semester. The maximum number of graduates from the 2009 cohort is $17 / 24$ or $71 \%$. Seven (29\%) of the 2009 cohort students left the university without graduating. The preceding analysis of graduation rates produced some interesting observations.

There appeared to be a significant difference in graduation rates (and retention rates) for students in the Math ACT score subgroups of 17-19 and 20-25. Partitioning the 24 students in the 2009 cohort in these two subgroups results in small numbers of students in each; however, some very interesting results are revealed. Table 4 shows the 4 year (May 2013) and 4.5 Year (December 2013) School of Engineering graduation rates for the 2009 SEEP cohort partitioned into ACT Math scores of 17-19 (11 students), 20-25 (13 students) and 17-25 (all 24 students). Somewhat surprising, zero of 11 students with ACT Math scores from 17-19 have graduated with a major in the School of Engineering while 7 of 13 in the ACT Math score range of 20-25 have graduated. One other student from each group remains enrolled as a Computer Engineering major in the spring semester 2014. Table 5 shows the 4 year and 4.5 year STEM graduation rates by ACT Math score groups. Table 5 reveals there were two other STEM graduates (Industrial Technology and Earth System Sciences) that both came from the 17-19 ACT Math score group. In addition to the two Computer Engineering majors still enrolled, one other STEM major 
(Biology) remains enrolled in spring 2014. Additional graduates are expected in May 2014 from this cohort.

\begin{tabular}{|c|c|c|c|}
\hline \multicolumn{4}{|c|}{ Rates; SEEP } \\
\hline 2009 Cohort & ACT Math 17-19 & ACT Math 20-25 & ACT Math 17-25 \\
\hline 4 Year & $0 / 11=0 \%$ & $3 / 13=23 \%$ & $3 / 24=12.5 \%$ \\
\hline 4.5 Year & $0 / 11=0 \% *$ & $7 / 13=54 \% *$ & $7 / 24=29.2 \% * *$ \\
\hline
\end{tabular}

*1 still enrolled in Computer Engineering; ** 2 still enrolled in Computer Engineering

\begin{tabular}{|c|c|c|c|}
\hline \multicolumn{5}{c}{ Table 5 } & STEM Graduation Rates SEEP & \\
\hline 2009 Cohort & ACT Math 17-19 & ACT Math 20-25 & ACT Math 17-25 \\
\hline 4 Year & $0 / 11=0 \%$ & $3 / 13=23 \%$ & $3 / 24=12.5 \%$ \\
\hline 4.5 Year & $2 / 11=18 \%$ & $7 / 13=54 \%$ & $9 / 24=37.5 \%$ \\
\hline
\end{tabular}

The insight revealed by Tables 4 and 5 above appears to imply that there are significant differences in School of Engineering graduation rates for the ACT Math score groups of 17-19 and 20-25. Seven (7/13) engineers have graduated from the group with ACT Math scores of 2025 while zero (0/11) have graduated from the group with ACT Math scores of 17-19. Five of the 11 students in the 17-19 ACT Math score group remain enrolled in the university (2 STEM majors, Biology and Computer Engineering, and 3 non-STEM majors). The remaining four students in the 17-19 group left the university without graduating. Three of the 13 students in the 20-25 ACT Math score group remain enrolled in the university (1 STEM major in Computer Engineering and 2 non-STEM majors). The remaining three students in the 20-25 group left the university without graduating.

Although the numbers of students are small, indications are that the SEEP program increases graduation rates in a School of Engineering major, especially for the 20-25 ACT Math score group. The summer program may well increase graduation rates and STEM graduation rates for the entire group of (17-25) ACT Math score students. Another two to five years of data with larger cohorts should enable a more quantifiable set of observations. It appears the time to graduate has been reduced by 0.5 to 1.0 years.

The quantitative data, albeit limited with respect to the total number of students to date, presented tends to credit the emerging success in graduation rates to the SEEP summer program. Qualitatively speaking the other aspects of the program certainly have a contribution to graduation success as an engineering major. During the first summer, the SEEP students develop a bond with one another that carries over throughout their undergraduate studies. They tend to help one another in future semesters when some are experiencing challenges. Discussions with students corroborate this sense of a community of engineering learners among the individual SEEP cohorts. An additional aspect of the SEEP program that contributes to cohort success is that two to four graduate students are employed half time to serve as a private tutor to the cohorts throughout their undergraduate engineering studies. This tutoring assistance is focused on the freshman and sophomore Calculus, Physics and Chemistry courses. The SEEP cohorts appear to be more active with student chapters of the professional societies (American Society of Civil Engineers, Association of Computing Machinery, Institute of Electrical and Electronic Engineers, Institute of Transportation Engineers, National Society of Black Engineers, 
Mississippi Engineering Society, Society of American Military Engineers and Society of Women Engineers). Over the next couple of years we intend to develop an interview strategy to attempt to better substantiate the these qualitative observations

\section{Conclusions}

Emerging data from a Summer Engineering Enrichment Program (SEEP) reveal the following impacts on graduation rates and times to graduate for engineering and computer science majors with ACT Math scores from 17-25.

(1). Graduation rates in a School of Engineering major (limited data) appear to be increased for 4 Year and 4.5 Year graduates (9.6\% to $12.5 \%$ and $15 \%$ to about $29 \%$ respectively) in the first summer cohort (2009).

(2). The effect of the summer program on retention became more pronounced from one year to two years and is projected to become even more pronounced for years three and four.

(3). The average time to graduate was reduced by at least $1 / 2$ year (from the limited data available).

(4). A very significant difference in graduation rates for the two ACT Math score subgroups of 17-19 and 20-25 was revealed. To date, 0\% (0/11) of the 17-19 ACT Math subgroup (11 students) graduated in 41/2 years while 54\% (7/13) of the 20-25 ACT Math subgroup (13 students) graduated in $4 \frac{1}{2}$ years. This conclusion will not change markedly with time since only one engineering major in each group remains enrolled.

(5). An extension of conclusion 4 would seem to be that the summer engineering enrichment program appears to increase graduation rates in engineering for first time freshman with ACT Math scores of 20-25 to comparable levels for students with higher ACT Math scores.

(6). Two to five more years of data will produce statistically significant results; however, emerging trends revealed by these data are expected to persist regardless of whether they become more or less pronounced.

\section{Acknowledgements}

The authors wish to thank the reviewers for insightful comments and suggestions which undoubtedly enhanced this paper. The authors wish to gratefully acknowledge the US Department of Education Title III Program HBCUCCRA No. P031B085092 for supporting the SEEP program for engineers at JSU for the summer cohorts of 2009 and 2010, and HBCUCCRA No.P031B100014 for supporting the summer bridge program 2011 through 2015. We acknowledge Dr. Mary B. Myles, JSU who is the Title III Principle Investigator and who was indispensable in encouraging the initiation and continuation of the SEEP program. Dr. Richard A. Alo', Dean, of the College of Science, Engineering and Technology is acknowledged for supporting the continuation of this effort. We wish to acknowledge Dr. Rosella L. Houston, 
Institutional Data Manager and Ms. Sylvia K. Wynne, Systems Analyst for their full support and assistance in obtaining the ACT data from the data archives of the Division of Institutional Research where these data were officially maintained for the university. We wish to acknowledge the three Department Chairs and their key staff who supported the effort. These are Dr. Mahmoud Manzoul and Ms. LaToya Pritchard in the Computer Engineering Department; Dr. Farshad Amini and Ms. Shanetta Crisler in the Civil and Environmental Engineering Department and Dr. Gordon W. Skelton, and Ms. Evette Stewart in the Computer Science Department. My tireless and dedicated Administrative Assistant, Ms. La Shon N. Lowe is gratefully acknowledged. Mrs. Josie A. Latham, SEEP program coordinator is acknowledged for her continuous participation and assistance in gathering information used, and most importantly for her dedication and excellence in managing the SEEP program.

\section{References}

[1] A. Reyes, Mary R. Anderson-Rowland, Mary Ann McCartney, "Student Success: What Factors Influence Persistence?”, 29th ASEE/IEEE Frontiers In Education Conference, November, 1999.

[2] John Nicklow, et al., “A Short-Term Assessment of A multi-Faceted Engineering Retention Program”, 39th ASEE/IEEE Frontiers In Education Conference, October, 2009.

[3] Jim Gleason, et al., "Integrated Engineering Math-Based Summer Bridge Program for Student Retention”, Advances in Engineering Education, Summer 2010, Volume 2, Number 2.

[4] Abhihit Nagchaudhuri, Gurbax Singh, "Summer Engineering Bridge Program at the University of Maryland Eastern Shore: Objectives and Enrichment Activities”, Proceedings of the 2001 American Society for Engineering Education Annual Conference \& Exposition, 2001.

[5] Maria A. Reyes, Mary R. Anderson-Rowland, Mary Ann McCartney, “Freshman Introductory Engineering Seminar Course: Couples with Bridge Program Equals Academic Success and Retention”, Frontiers in Education Conference, 1998.

[6] Donna S. Reese, Robert Green, and Martha Smith, “A Pre-Engineering class to Help Transition Students Into an Engineering Major”, ASEE Southeast Section Conference, Blacksburg, Virginia, April 2010.

[7] Donna S. Reese, “Assessing the Effect on Retention of an Engineering Living/Learning Community”, ASEE Southeast Section Conference, Charleston, South Carolina, April 2011.

[8] Pablo Biswas and Runchang Lin, "Improve Retention Rate and Performance of Students in STEM Field Using a Virtual Teaching Assistant System”, ASEE Annual Conference, 2013

[9] Patricia R.Backer, Emily L. Allen, and Janet Sundrud, “Assessment of First-Year Experiences at SJSU”, ASEE Annual Conference \& Exposition, 2011.

[10] Pablo Arenaz, Walter Fisher, Benjamin Flores, Connie Della-Piana, "Cir Les: A Comprehensive First Year Program For Entering Engineering and Science Students”, ASEE Annual Conference 2001. 
[11] Summer Dann, Paige Davis, and Warren N. Waggenspack, Jr., “Implementing a Bridge Camp and Intro. Course: Lessons Learned from a Phase 1 STEP Grant”, ASEE Annual Conference, 2012

[12] Marcia William, Xiaochun Jiang, Sanjiv Sarin and Gerald Watson, "Evaluation of the Nc Lsamp Project Using Graduation Rate and Gatekeeping Course Performance”, ASEE Annual Conference \& Exposition 2007 